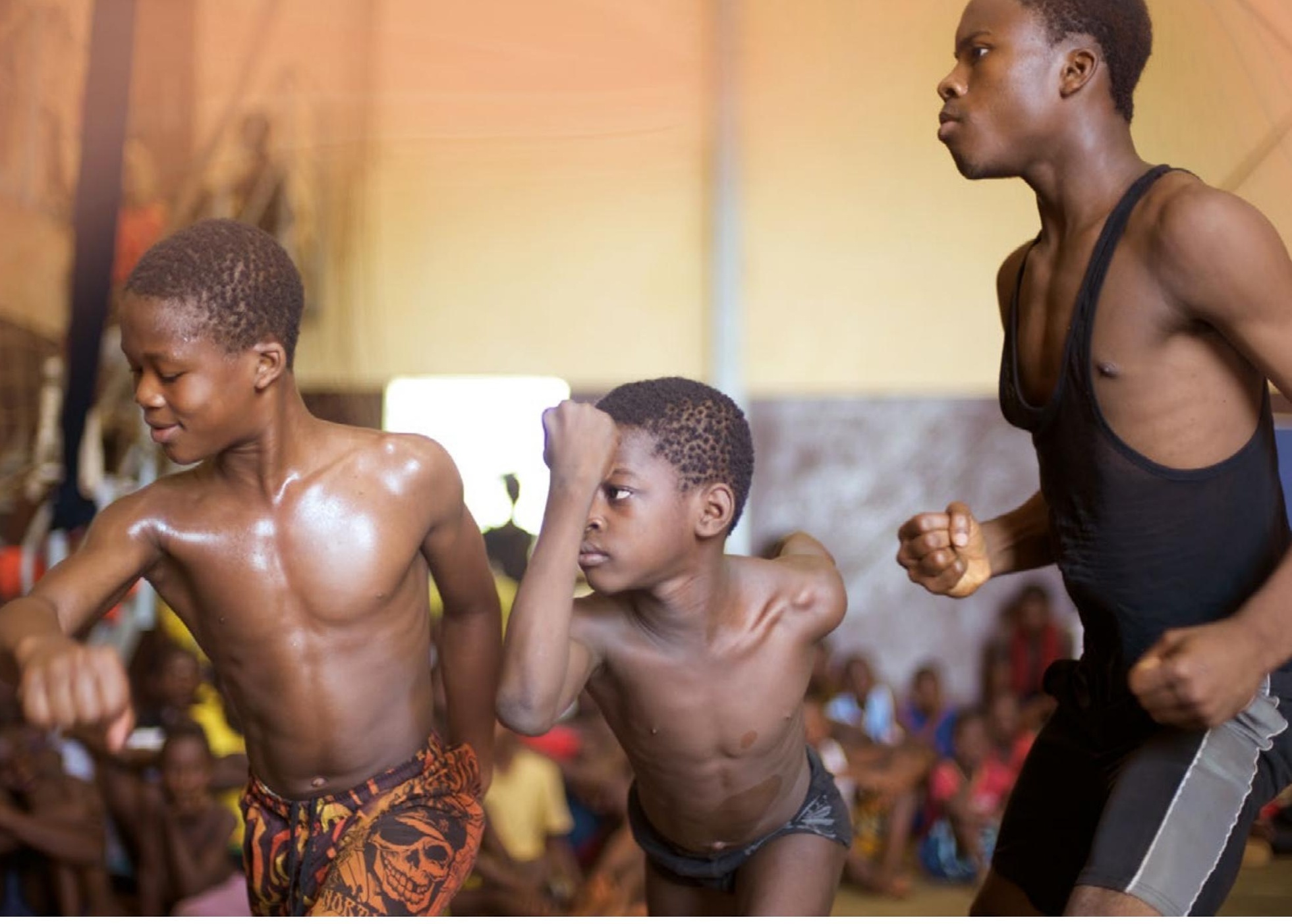

\title{
FORMAÇÃO DOCENTE E CONSCIÊNCIA HISTÓRICA: UM ESTUDO DE CASO - PIBID/HISTÓRIA/CERES
}

\section{RESUMO}

O artigo apresenta a experiência de planejamento e intervenção temática das relações étnico-raciais e a Lei 10.639/03 no âmbito do subprojeto História PIBID, na Escola Estadual Antônio Aladim, na cidade de Caicó-RN, no ano de 2015. Para tanto, levou-se em consideração na reflexão que se apresenta, o trabalho da supervisão a cargo da professora Maria de Lourdes Pereira de Medeiros no planejamento das atividades de intervenção com os bolsistas PIBID para sala de aula. Nesse trabalho, enfatiza-se o protagonismo do professor, a construção da consciência histórica no aluno e a formação docente.

Palavras-chave: Lei 10.639/03.

Consciência Histórica. Formação Docente.

Relações Étnico-Raciais. 


\section{PLANEJANDO AS INTERVENÇÕES}

O ano de 2015 foi dedicado à construção de uma experiência de formação de professores ligados à prática de sala de aula e às intervenções do PIBID, subprojeto de História/ Caicó, no Ensino Médio na Escola Estadual Antônio Aladim.

Essa experiência foi e tem sido sui generis naquele espaço ao mostrar como o protagonismo do professor em sala de aula pode fazer a diferença na construção de uma consciência histórica sobre as temáticas relacionadas à História da África e da Cultura Afro-Brasileira, em seus desafios históricos específicos. Isso evidencia, por parte de alguns profissionais, uma preocupação em se trabalhar a Lei 10.639/03 no cotidiano da escola e do aluno, de forma que, ao abordá-la através de discussões de conteúdos e da realidade social dos alunos, está-se renovando uma discussão historicamente marginalizada, sendo carente de uma abordagem crítica e pontual.

Partindo desse pressuposto, compreende-se a importância das aulas de História como ponte para a construção do conceito de consciência histórica, entendido como aquele que "funciona como um modo específico de orientação nas situações reais da vida presente, tendo como função específica ajudar-nos a compreender a realidade passada para compreender a realidade presente" (GARCIA; SCHMIDT, 2005, p. 300-301). Por outras palavras, os alunos da escola quando estimulados adequadamente serão capazes de fazer conexões entre os acontecimentos do passado e o seu universo contemporâneo e cotidiano.

A convocatória da Lei 10.639/03 e o conceito de consciência histórica vem a se somar ao relato problematizado das atividades programadas e executadas no âmbito do PIBID, subprojeto História, na referida escola Antônio Aladim no ano de 2015. Para o momento, estamos abordando apenas o planejamento para as intervenções na escola. Diante disso, Gomes
(2012, p. 108) indaga: "como o campo da formação de professores e professoras lida com essas rupturas? Como a alteração da LDB pela Lei ${ }^{\circ} 10.639 / 03$ se insere nesse contexto"?

Em primeira demanda, é o protagonismo do professor na sua escola, em sua sala de aula "que garante singularidade e importância à legislação em referência, mas a natureza do desafio que coloca para o saber escolar alterar visões de mundo, redimensionar a memória, criticar mitos e enfrentar preconceitos" (COELHO; COELHO, 2013, p. 96). Ainda como afirma Coelho (2013, p.96), a escola e seus instrumentos como "o discurso docente, o currículo escolar, os seus procedimentos, a literatura didática" reproduzem discursos e reforçam dada visão europeizante corrente nas temáticas relacionadas ao negro e ao indígena. Também aponta em sua análise que o professor ao trazer o debate atual pautado pelas referidas leis acima para a cultura escolar permite "alterar visões de mundo, redimensionar memória, criticar mitos e enfrentar preconceitos" (COELHO, 2013, p. 96).

Partindo dessa perspectiva de análise, o objetivo deste relato de experiência é problematizar como a atuação da professora supervisora do subprojeto História/Caicó, Maria de Lourdes Pereira de Medeiros, do Ensino Médio, lotada na Escola Estadual Antônio Aladim, constrói um espaço duplo na formação dos alunos, seja os discentes regulares daquela instituição ou os bolsistas PIBID ao trazer para discussão as temáticas relacionadas à História da África e à Cultura Afro-brasileira. O espaço duplo de formação dá-se da seguinte forma: ao se planejar e discutir os temas das intervenções, os alunos em formação para docência são submetidos a um processo de reflexão de ruptura epistemológica.

É que a lei 10.639/03 direciona a percepção de que a cultura negra é "tratada de maneira desconectada com a vida social mais 
ampla" (GOMES, 2012, p. 104). Por outras palavras, o docente em formação percebe que há um descompasso entre o seu cotidiano e o que é trabalhado nas escolas, por meio do currículo escolar, um modelo monocultural, que não comporta a diversidade cultural $\mathrm{e}$ étnico-racial em sala de aula. Também, ao construir esse tipo de abordagem para sala de aula possibilita aos alunos a compreensão de como as diferenças culturais entre homens e mulheres são naturalizadas.

O movimento de intervenção começou com o processo de planejamento docente, com os bolsistas, em que se buscou elencar quais eixos temáticos seriam discutidos com os alunos da escola. No ano de 2015, optou-se trabalhar com a temática étnico-racial, sendo a África o tema escolhido nos aspectos da arte, religião, literatura, dança e culinária. As intervenções ocorreram nas turmas de $1^{\circ}, 2^{\circ} \mathrm{e}$ $3^{\circ}$ Ano do Ensino Médio.

A preocupação da supervisão e dos alunos bolsistas se pautou pela construção de uma relação de proximidade ou pontes entre os conteúdos e o cotidiano do aluno na atualidade. Como exemplo, temos que, na intervenção realizada no $1^{\circ}$ Ano do EM, da citada escola, o tema abordado foi o surgimento dos seres humanos. As questões norteadoras construídas para mobilização dos alunos em primeira instância foi trabalhar: O que os homens de hoje podem fazer e o que os da Pré-História não podiam realizar? Essa discussão comparativa, a partir da experiência do aluno hoje, permitiu que pudessem perceber a categoria do tempo como uma evidência do processo de hominização. Além disso, incorporar nestas discussões as narrativas dos mitos de criação, seja ele iorubá ou o mito cristão, possibilitou aos alunos perceberem as diferenças entre as sociedades.

De acordo com a professora supervisora Maria de Lourdes Medeiros:
Com relação especificamente a África, as intervenções objetivaram refletir acerca da diversidade das produções culturais humanas na história, a partir de um olhar sobre as civilizações africanas, como também conhecer aspectos de algumas culturas da África através da arte, especificamente, a escultura. Diferenciando as de Benin, Ilê e Ifê de acordo com as visões de mundo. (MEDEIROS, 2016. Caicó. Entrevista concedida à Juciene Andrade).

No planejamento de intervenção para a turma do $2^{\circ}$ Ano do Ensino Médio, o tema trabalhado foi África: terra de muitas divindades e Orixás. A abordagem acerca do paradigma religioso em sala de aula permitiu ao aluno entrar em contato com as matrizes africanas do crer. Necessariamente, esta temática não é considerada nova, porém "se traduzem no novo para educadores entorpecidos pelo olhar hegemônico de inspiração eurocêntrica (...)" (SILVA, 2005, p. 121).

Em conversas problematizadoras acerca de seus planejamentos, a professora supervisora apontou:

\begin{abstract}
Abordando-se além da questão religiosa, o contexto em que o continente africano estava inserido, no período da colonização, fazendo um paralelo com o passado desse continente e o Brasil, a partir da cultura afro-brasileira. Foram apresentados os Orixás e sua influência e presença no cotidiano brasileiro, atentando para o conhecimento, respeito e reconhecimento, relacionado as tradições religiosas africanas com a católica. (MEDEIROS, 2016. Caicó. Entrevista concedida à Juciene Andrade).
\end{abstract}

Ao se planejar essa abordagem, a professora Maria de Lourdes Pereira de Medeiros e os bolsistas buscaram construir pontes entre a experiência histórica africana e brasileira. Inserir no campo do ensino aprendizagem a relação direta entre o exercício do crer no continente africano e sua herança religiosa em território brasileiro. Segundo Gomes e Munanga (2006, p. 139), a religiosidade negra é diversa, "No Brasil, os nossos ancestrais africanos enriqueceram a nossa cultura com diferentes expressões e 
formas de se relacionar com o mundo mágico e sobrenatural". Ao se construir essa estratégia de abordagem sobre os signos da religiosidade africana e, por conseguinte brasileira, se institui um espaço em que podem ser retrabalhados os equívocos reforçados por uma cultura escolar de matrizes teórico-metodológicas europeias. Segundo Silva (2005, p. 125), o temor dos referentes da população afrodescendente "alcançou os bancos escolares e acabou sendo responsável por uma série de erros que se mantiveram em uma espécie de círculo vicioso entre educadores e educandos". Sendo reforçadores de uma prática religiosa brasileira, a católica, e excludentes com outras formas de religiosidades entendidas como seitas, a exemplo do candomblé e da umbanda. Esquece-se de abordar que as religiões de matrizes afro-brasileiras, formaram-se num sincretismo, como afirma (GOMES; MUNANGA, 2006, p. 142), "na fusão de diferentes elementos culturais com o catolicismo, e, em grau menor com as religiões indígenas".

Dessa forma, o papel do professor é desconstruir estes lugares, tomando para si o protagonismo dessa ação.

Um terceiro tema abordado no planejamento das intervenções foi a compreensão de que a cultura brasileira está fortemente ligada às raízes africanas, e elegendo-se a música e a culinária como espaço de reflexão e percepção dessa diversidade cultural.

Segundo a professora supervisora:

\begin{abstract}
Os ritmos trabalhados foram: semba, kizumba, lundu, ahouach, capoeira e kuduro. Outro tema trabalhado foi a culinária africana e sua importância para a cultura brasileira, (sic) foram vistos vários pratos culinários, ingredientes e modos de fazer, como também sua influência-presença na mesa do brasileiro. Como material didático foram confeccionados um álbum e um caderno de receitas. (...) a partir dos trabalhos dos pibidianos, pode-se entender como a cultura africana é rica e está presente no cotidiano dos brasileiros. (MEDEIROS, L. 2016. Caicó. Entrevista concedida à Juciene Andrade).
\end{abstract}

Dos estilos, ritmos e danças de experiência africana a semba ou masemba é um dos modos musicais mais populares de Angola e significa umbigada. Em tradições angolanas posteriores, um estilo de dança, em que os movimentos incorriam ao encontro dos corpos masculinos e femininos. Assim como o semba, Kizomba, lundu, ahouach e kuduro são danças e ou ritmos originários da África, mas que vieram para o Brasil trazidos pelos negros de tradição angolana, banto e que sofreram releituras de adaptabilidade ao cotidiano negro no Brasil. Assim como os ritmos/danças, a culinária foi um tema escolhido pela proximidade com que pode ser trabalhada o cotidiano do aluno e dessa forma, instrumentalizar e fomentar a consciência histórica. Este conceito é necessário para que se possa quebrar preconceitos e visões estereotipadas acerca da tradição africana ou afro-brasileira.

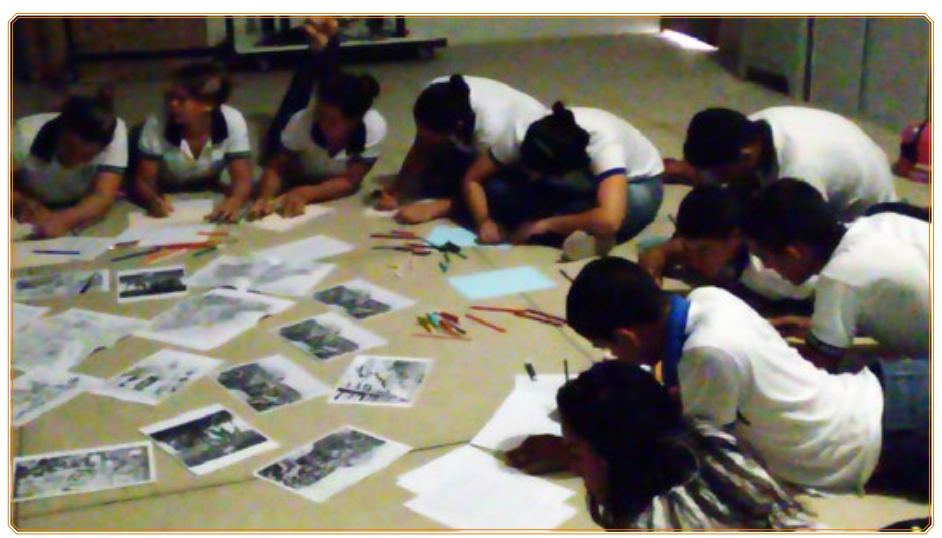

Figura 1 - Alunos elaborando material didático

Fonte: Maria de Lourdes Pereira de Medeiros. Subprojeto História - Caicó. Escola Estadual Antônio Aladim 
Nas intervenções, tanto os bolsistas quanto os alunos da escola, metodologicamente foram incitados a pesquisarem comidas africanas e a construírem um livro de receitas. Foram pesquisadas receitas culinárias da África do Sul, do Egito, Etiópia, Marrocos, Angola, comidas como: arroz amarelo, pastel doce com banana, bolinho-de-grão-de-bico, baba ganoush,

Wot, Ingera, bolo marroquino, doce de banana respectivamente.

O resultado da intervenção foi: a aplicabilidade da lei 10.639/03 na condição de convocar a temática africana e afro-brasileira para sala de aula, debater e instaurar outro ambiente de ressignificação e olhares sobre a cultura negra, demonstrando que no cotidiano o exercício do crer, das danças, ritmos, músicas, culinária representam uma herança profunda da experiência negra no Brasil. Não apenas a narrativa da escravidão como única bagagem do legado africano e afro-brasileiro, mas a ênfase em aspectos históricos, sociais e culturais que ficam à margem do trabalho curricular.

Dessa forma, como aponta (GOMES, 2012, p. 106), a produção de um outro paradigma epistemológico implica:

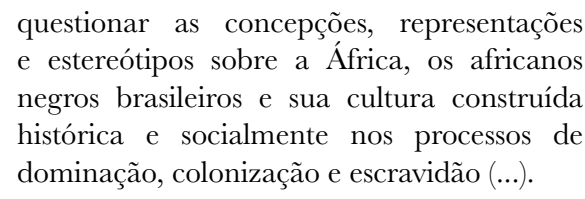
e estereótipos sobre a África, os africanos negros brasileiros e sua cultura construída histórica e socialmente nos processos de dominação, colonização e escravidão (...).

Portanto, resulta num trabalho de desconstrução dos lugares tradicionalmente voltados para a história dos africanos e afro-brasileiros. Isso começa pela construção de pontes entre o cotidiano do aluno e sua consciência histórica em relação com uma visão problematizadora dos eventos históricos.

\section{TEACHING TRAINING AND HISTORICAL CONSCIOUSNESS: A CASE STUDY - PIBID/HISTORY/CERES}

\section{ABSTRACT}

This article presents the experience of planning and thematic intervention of ethnicracial relations and Law 10.639/03 within the scope of the PIBID History subproject, at the Antônio Aladim State School, in the city of Caicó, Rio Grande do Norte state, in the year 2015. To do so, the work of supervision by the teacher Maria de Lourdes Pereira de Medeiros in the planning of the intervention activities with the
PIBID grantees for the classroom was taken into consideration in the reflection that is presented. In this work, the emphasis is placed on the role of the teacher, the construction of historical consciousness in the student and teacher training.

Key-words: Law 10.639/03. Historical Consciousness. Teacher training. Racial Ethnic Relations. 


\section{REFERÊNCIAS}

AZEVEDO, Grislane. O planejamento docente na aula de História. Princípios teóricos-metodológicos. Revista metáfora educacional, Salvador, n. 14, p. 3-28, jun. 2013.

COELHO, Mauro Gezar; COELHO, Wilma de Nazaré Baía. Jogando verde e colhendo maduro: Historiografia e saber histórico escolar no Ensino de História da África e da Cultura Afro-Brasileira.

Revista territórios e fronteiras, Mato Grosso, v. 6, n. 3, p. 93-107, dez. 2013.

GARCIA, Tânia Maria Braga; SCHMIDT, Maria Auxiliadora Moreira dos Santos. A Formação da consciência histórica de alunos e professores e o cotidiano em aulas de História. Cadernos CEDES, São Paulo, v. 25, n. 67, p. 297-308, set./dez. 2005.

GOMES, Nilma Lino; MUNANGA, Kabengele. O Negro no Brasil de hoje. São Paulo: Global, 2006.

GOMES, Nilma Lino. Relações étnico-raciais, educação e descolonização dos currículos. Revista currículo sem fronteiras, Porto, v. 12, p. 98-109, jan./abr. 2012.

MEDEIROS, 2016. Caicó. Entrevista concedida à Juciene Andrade

SILVA, Nelson Fernando Inocêncio da. Africanidade e Religiosidade: uma possibilidade de abordagem sobre as sagradas matrizes africanas na escola. In:

Educação anti-ra-

cista: caminhos abertos pela Lei Federal no 10.639/03. Brasília: Ministério da Educação/ Secretaria de Educação Continuada, Alfabetização e Diversidade, 2005. p. 121-130. 